Www.jmscr.igmpublication.org

Impact Factor (SJIF): 6.379

Index Copernicus Value: 79.54

ISSN (e)-2347-176x ISSN (p) 2455-0450

crossrefDOI: https://dx.doi.org/10.18535/jmscr/v6i9.06

\title{
Study on Lipid Profile Pattern in Acute Coronary Syndrome Patients with Special Relation to HDL Cholesterol
}

\author{
Authors \\ Lokesh N K ${ }^{1^{*}}$, Shivakumar K $\mathbf{M}^{2}$ \\ ${ }^{1}$ Assistant Professor Dept of General Medicine MIMS Mandya Karnataka \\ ${ }^{2}$ Professor Dept of General Medicine MIMS Mandya Karnataka \\ *Corresponding Author \\ Lokesh N K \\ Assistant Professor, Dept of General Medicine MIMS Mandya 571401 Karnataka, India \\ Email: lahari2k253@gmail.com
}

\begin{abstract}
Background: Acute coronary syndrome was one of the most common cause for mortality and morbidity all over the world. Epicardial arterial atheroscleorosis was the main risk factor for coronary heart disease. Dyslipedemia is one of the most important risk factor for atherosclerosis and its consequences.

Aims and Objectives: To study lipid profile pattern in acute coronary syndrome patients

Materials and Methods: It was a retrospective study conducted between January 2017 to December 2017 at Govt Hospital MIMS Mandya. As per inclusion criteria and exclusion criteria cases are included and excluded, and a prestructured proforma was used, and data were entered. A standard serum lipid profile measures the concentration of total and high-density lipoprotein (HDL) cholesterol as well as the triglycerides.

Results: Out of 62 patients 26 were females (41.9\%) 36 were males (58.1\%). Most common age group was 50 to 60 years. Out of 62 patients 32(51,6) were admitted with STEMI ,20 were (32.3\%) admitted with NSTEMI. Average total Cholesterol was $195.5 \mathrm{mg} / \mathrm{dl}$, LDL-C was $119.5 \mathrm{mg} / \mathrm{dl}$, HDL-C was $38.4 \mathrm{mg} / \mathrm{dl}$ and TG was $179.1 \mathrm{mg} / \mathrm{dl}$ respectively.

Conclusion: Increased LDL-C and decreased HDL-C was one of the important lipid abnormality causing CHD. It is important to advice regarding good dietary habits and exercise to prevent such events at community level.

Keywords: STEMI, NSTEMI, UA, LDL-C, HDL-C.
\end{abstract}

\section{Introduction}

Atherosclerosis remains the major cause of death and premature disability in developed societies. Moreover, current predictions estimate that by the year 2020 cardiovascular diseases, notably atherosclerosis, will become the leading global cause of total disease burden. Although many generalized or systemic risk factors predispose to its development, atherosclerosis affects various regions of the circulation preferentially and has distinct clinical manifestations that depend on the particular circulatory bed affected. Atherosclerosis of the coronary arteries commonly causes myocardial infarction (MI) ${ }^{1}$. 
Abnormalities in plasma lipoproteins and derangements in lipid metabolism rank among the most firmly established and best understood risk factors for atherosclerosis ${ }^{1}$.

The pathogenesis of acute myocardial infarction (AMI) is multifactorial however, several studies have implicated impaired lipid metabolism as one of the crucial factors in the development of this disease. The risk of AMI was associated with increase in LDL and a decrease in HDL in both Asians and non Asians. Lower concentrations of serum HDL and higher serum TG were found to beindependent risk factors ${ }^{2}$.

Ischemic heart disease (IHD) is a condition in which there is an inadequate supply of blood and oxygen to a portion of the myocardium; it typically occurs when there is an imbalance between myocardial oxygen supply and demand. The most common cause of myocardial ischemia is atherosclerotic disease of an epicardial coronary artery (or arteries) sufficient to cause a regional reduction in myocardial blood flow and inadequate perfusion of the myocardium supplied by the involved coronary artery.

Epicardial coronary arteries are the major site of atherosclerotic disease. The major risk factors for atherosclerosis (high levels of plasma low-density lipoprotein [LDL], low plasma high-density lipoprotein [HDL], cigarette smoking, hypertension, and diabetes mellitus disturb the normal functions of the vascular endothelium ${ }^{23}$.

Total blood cholesterol consists of low-density lipoprotein cholesterol (LDL-C), which is the largest component of total cholesterol (TC), i.e., $60-70 \%$ of TC. LDL-C is very atherogenic and it should be decreased and represents the major cause of CHD. HDL-C is one of important lipoproteins and is very potential to prevent atherosclerosis by changing the "biology" of arterial wall lesion, without being affected by LDL-C level. Triglycerides (TG) may cause endothelial dysfunction and may stimulate macrophages migration into endothelium ${ }^{4}$.

Now days acute coronary syndrome increasingly more common in indianpopulation, may be because of multifactorial among most important is dietary habits, importantly atherogenic diet and life style.

\section{Aims and Objectives}

Study of lipid profile patterns in patients admitted with acute coronary syndrome (UA/non-ST elevation myocardial infarction [NSTEMI]/ST elevation myocardial infarction [STEMI]).

\section{Materials Methods}

It was a retrospective study conducted on patients admitted to ICCU wards of Govt Hospital dept of general medicine MIMS Mandya between January 2017 to December 2017.

\section{Inclusion criteria}

Age $>30$ years

New cases of acute coronary syndrome

\section{Exclusion criteria}

The patients with previous history of MI are excluded.

Acute coronary syndrome that occur secondary to other reasons such as anemia, trauma or non cardiac surgery is excluded.

The diagnosis of UA is based largely on the clinical presentation. Typically, chest discomfort is severe and has at least one of three features: (1) it occurs at rest (or with minimal exertion), lasting $>10$ minutes; (2) it is of relatively recent onset (i.e., within the prior 2 weeks); and/or (3) it occurs with a crescendo pattern (i.e., distinctly more severe, prolonged, or frequent than previous episodes)

The diagnosis of NSTEMI is established if a patient with above clinical features develops evidence of myocardial necrosis, as reflected in abnormally elevated levels of biomarkers of cardiac necrosis.

The diagnosis STEMI by detection of a rise and/or fall of cardiac biomarkers values (preferably cardiac troponin (cTn) with at least one value above the $99^{\text {th }}$ percentile upper reference limit and with at least one of the following:

Symptoms of ischemia 
New or presumed new significant ST-T changes or new left bundle branch block.

Development of new pathologic q waves in ECG. Imaging evidence of new loss of viable myocardium or new regional motion abnormalities.

Identification of an intracoronary thrombus by angiography or autopsy.

Data regarding age, sex, occupation, risk factors like DM, HTN, Smoking, Family history ,type of MI, Lipid profile pattern and reports of 2D Echo and cardiac enzymes level and associated comorbid conditions were collected from the hospital records and documented in the prestructured proforma. Then, the data were analyzed by the descriptive statistical method. Ethical clearance was taken from the ethical committee.

\section{Results}

Total 62 patients data collected from records ,out of 62 patients $36(58.1 \%)$ were males and 26 were females (41.9\%).Most common age group affected was 51-60 years(37\%) followed by 61-70 years $(25.8 \%)$, only $6(9.7 \%)$ patients belong to less than 40 years age.

Out of 62 patients 24(38.3\%) were diabetic and 38 $(61.3 \%)$ were chronic smoker.36 (58.1\%) patients were suffering from hypertension. 27(43.5\%) patients were chronic alcoholic.

Most common presenting symptom was chest pain (90\%), followed by breathlessness (6\%). Most common type of ACS was STEMI (51.5\%), NSTEMI (32.3\%), UA (16.7\%). (Table-1)

Table-1 Distribution of patients into various types of acute coronary syndromes

\begin{tabular}{|l|r|}
\hline $\begin{array}{l}\text { Type of ACS } \\
\text { patients }\end{array}$ & $\begin{array}{r}\text { Number of } \\
\text { patients (\%) }\end{array}$ \\
\hline Anterior wall MI & $18(29 \%)$ \\
\hline Inferior wall MI & $10(16.7 \%)$ \\
\hline Anterolateral MI & $4(6.5 \%)$ \\
\hline $\begin{array}{l}\text { Anterior wall } \\
\text { NSTEMI }\end{array}$ & $12(19.4 \%)$ \\
\hline $\begin{array}{l}\text { Inferior wall } \\
\text { NSTEMI }\end{array}$ & $8(12.9 \%)$ \\
\hline UA & $10(16.7 \%)$ \\
\hline
\end{tabular}

Average total cholesterol was $195.47 \mathrm{mg} / \mathrm{dl}$, LDLC was $119.5 \mathrm{mg} / \mathrm{dl}$, HDL-C was $38.4 \mathrm{mg} / \mathrm{dl}$ and TG was $179.1 \mathrm{mg} / \mathrm{dl}$ respectively.

$12(19.4 \%)$ patients had >160 mg/dl LDL-C,32 $(51.6 \%)$ patients had $>200 \mathrm{mg} / \mathrm{dl}$ total cholesterol, $32(51.6 \%)$ patients had $<40 \mathrm{mg} / \mathrm{dl}$ HDL-C and $5(8.1 \%)$ patients had $>400 \mathrm{mg} / \mathrm{dl}$ TG respectively.

\section{Discussion}

In the present study incidence of ACS was more common in 51-60(37\%) year's group patients, followed by 61-70 (25.8\%) years group patients. Study done by Prashanthkumar et al titled Study of Lipid Profile in Acute Myocardial Infarction within 24 Hours showed similar results. (Tablw-2)

Table-2 Comparison of different clinical profile

\begin{tabular}{|l|c|c|}
\hline Clinical profile & $\begin{array}{c}\text { Prashanthkumar } \\
\text { et } \mathrm{al}^{3}(\%)\end{array}$ & $\begin{array}{c}\text { Present } \\
\text { study }(\%)\end{array}$ \\
\hline $\begin{array}{l}\text { Most common age } \\
\text { group }\end{array}$ & $51-60(37 \%)$ & $\begin{array}{c}61- \\
70(36.6 \%)\end{array}$ \\
\hline $\begin{array}{l}\text { Incidence in <40 } \\
\text { years }\end{array}$ & $6(9.7 \%)$ & $6(10 \%)$ \\
\hline DM & $24(38.7 \%)$ & $10(16.7 \%)$ \\
\hline SMOKER & $38(61.3 \%)$ & $22(36.6 \%)$ \\
\hline Hypertension & $26(41.9 \%)$ & $25(41.6 \%)$ \\
\hline Alcohal & $27(43.5 \%)$ & $26(43.3 \%)$ \\
\hline
\end{tabular}

Present study showed most common lipid abnormality was increased LDL-C and decreased HDL-C. Study done by Prashanth Kumar et $\mathrm{al}^{3}$ showed similar results. Study done by Md Zahid Alam et $\mathrm{al}^{4}$ titled Pattern of Dyslipidemia in different type of Myocardial Infarction showed similar results.

Average total Cholesterol was $195.5 \mathrm{mg} / \mathrm{dl}$, LDL$\mathrm{C}$ was $119.5 \mathrm{mg} / \mathrm{dl}$, HDL-C was $38.4 \mathrm{mg} / \mathrm{dl}$ and TG was $179.1 \mathrm{mg} / \mathrm{dl}$ respectively. Study done Prashanth Kumar et $\mathrm{al}^{3}$ showed, the average TC was $208.53 \mathrm{mg} / \mathrm{dl}$, TG was 168.73, HDL-C was $41.65 \mathrm{mg} / \mathrm{dl}$, mean LDL-C was $133.13 \mathrm{mg} / \mathrm{dl}$ respectively. (Table 3 )

In our study ratio of TC/HDL $>5$ and TG/HDL $>4$. According to the American Heart Association, the goal is to keep TC/HDL ratio < 5 and TG/HDL $<4$. A higher ratios indicates a higher risk of heart disease; a lower ratio indicates a lower risk. Study done by Md Zahid Alam et al showed similar results. 
Our study showed 51.6\% patients had HDL-C <40 $\mathrm{mg} / \mathrm{dl}$. It was very significant; this may be the reason for higher incidence of CHD in Indian population.

Average HDL-C in STEMI patients was 38.3 $\mathrm{mg} / \mathrm{dl}$, in NSTEMI patients was $37,3 \mathrm{mg} / \mathrm{dl}$ and in
UA patients was $40.87 \mathrm{mg} / \mathrm{dl}$ respectively.(Table 4)

Out of 62 patients $32(51.6 \%)$ patients had $>200$ $\mathrm{mg} / \mathrm{dl}$ total cholesterol, 12 (19.4\%) patients had $>160 \mathrm{mg} / \mathrm{dl}$ LDL-C,5 (8.1\%) patients had >400 $\mathrm{mg} / \mathrm{dl} \mathrm{TG}$ and 32(51,6\%) patients had $<40 \mathrm{mg} / \mathrm{dl}$ HDL-C.

Table 3 Lipid profile comparison with different studies

\begin{tabular}{|l|c|c|c|}
\hline Lipid parameter & Present study $(\mathrm{mg} / \mathrm{dl})$ & Prashanthkumar et al $^{3}(\mathrm{mg} / \mathrm{dl})$ & MdZahidAlam et al $^{4}(\mathrm{mg} / \mathrm{dl})$ \\
\hline TC & 195.5 & 208.53 & 195.7 \\
\hline LDL-C & 119.5 & 133.13 & 120.7 \\
\hline HDL-C & 38.4 & 41.65 & 37.14 \\
\hline TG & 179.1 & 168.73 & 152.8 \\
\hline
\end{tabular}

Table 4 Average Lipid profile in different ACS

\begin{tabular}{|l|c|c|c|c|c|c|c|c|}
\hline \multirow{2}{*}{ ACS } & \multicolumn{4}{|c|}{ Present study(mg/dl) } & \multicolumn{4}{c|}{ Md Zahid Alam et $^{4}(\mathrm{mg} / \mathrm{dl})$} \\
\cline { 2 - 10 } & TC & LDL-C & HDL-C & TG & TC & LDL-C & HDL-C & TG \\
\hline STEMI & 204.5 & 126.9 & 38.3 & 180.2 & 220.7 & 160.7 & 35.14 & 182.8 \\
\hline NSTEMI & 194.8 & 118.7 & 37.3 & 178.5 & 208.4 & 148.3 & 41.65 & 174.4 \\
\hline
\end{tabular}

\section{Conclusion}

In the present study has been observed ACS more common in males compared to females because of males had associated risk factors like DM, HTN, Smoking .Most common age group affected was 51-70 years, may be because of age factor and associated other risk factors. it was found that HDL-C was significantly low in most of the patients, that may be reason for more incidence of ACS events in Indian population. Hence, inference may be drawn from the present study that the patients who are having low HDLcholesterol are prone to develop myocardial infarction. This may be an important guideline for preventing CHD in future. It is important to advice regarding dietary habits and regular physical exercise to prevent to such events at community level.

\section{References}

1. Elliot $\mathrm{M}$ antman, Joseph Losacalzo. Harrison's principles of Internal Medicine 2015;293(19):1578-1598.

2. Paul M ridker, Peter Libby, Julie E Buring. Braunwalds Heart Disease. 2015;42 (10):891-931.
3. Prashanth Kumar et al,Study of Lipid Profile in Acute Myocardial Infarction within 24 Hours. Annals of Applied BioSciences; 2018;5(1): 2455-0396.

4. Md Zahid Alam et al,Pattern of Dyslipidemia in different type of Myocardial Infarction. Bangladesh Crit Care J; 2017 September; 5 (2): 106-109.

5. Bikash Dali, Clinical Profile, Dyslipidemia and ACS - a Correlation. Journal of Nepal Medical Association :2014 September; 52 (195):907-13.

6. Daulat Manurung, Lipid Profiles of Acute Coronary Syndrome Patients Hospitalized in ICCU of Cipto Mangunkusumo Hospital Division of Cardiology, Department of Internal Medicine Faculty of Medicine, University of Indonesia 2006:(38):196-201.

7. Sureshkumar, Clinical Study of Lipid Profile Pattern in Acute Coronary Syndromes. IJSS 2017:(5):174-177.

8. Karthikeyan G, Teo KK, Islam S, et al. Lipid profile, plasma apolipoproteins, and risk of a first myocardial infarction among Asians: an analysis from the Inter heart 
Study. J Am Coll Cardiol. 2009:(53):244253.

9. Haseeb A Khan, Abudallah S Allomida. Lipid profile of patients with acute myocardial infarction. NCBI: 2013:(3):17.

10. Balci B. The modification of serum lipids after acute coronary syndrome and importance in clinical practice. Curr Cardiol Rev. 2011;7(4):272-276. 